\title{
Hazardous gas areas on high-pressure gas pipelines in Poland
}

\author{
Łukasz Zabrzeski1,*, Lukasz Drążkiewicz ${ }^{2}$, Krystian Liszka ${ }^{1}$, Mariusz Laciak $^{1}$, and Piotr \\ Paszylk $^{1}$ \\ ${ }^{1}$ AGH University of Science and Technology, Faculty of Drilling, Oil and Gas, Department of Natural \\ Gas Engineering. Al. Mickiewicza 30, 30-059 Cracow, Poland, \\ ${ }^{2}$ The Main School of Fire Service, Faculty of Fire Safety Engineering, Słowackiego 52/54 St, 01-629 \\ Warszawa, Poland
}

\begin{abstract}
Natural gas transmission is strongly connected with fire and explosion safety. Generally, explosion hazard occurs, when at least $5 \%$ of natural gas is present in the atmospheric air. As high-pressure gas transmission infrastructure includes many potential sources of gas releases, both operational and accidental, many different cases should be considered. To properly face the potential hazard of explosive atmosphere formation, the hazardous zone should be estimated. There are some guidelines, describing the process of hazardous zones calculating. This paper compares calculations of such hazardous based on Polish and European standards which are also valid in Poland. Calculations are focused on releases that may occur on the safety block and relief valve systems.
\end{abstract}

\section{Introduction}

The natural gas transport with high pressure pipelines is a key part of the gas system. This energy carrier is a mixture of all light hydrocarbons having lower density than air and which are flammable. This causes that the mixture of natural gas and air may be explosive. This happens when the molar participation of blue fuel in air totals to about 5 to $15 \%$. The origin of explosions, their course and possible consequences and extent can be found, e.g. in [1] and [2].

The transmission network consists of a number of elements which are crucial for its proper operation. The explosion hazard will be present in places where these elements are localized, starting from pipelines to gas compression stations, but with different probability and range. This hazard can be counteracted with prevention measures and one of them is distinguishing the explosion hazard zone and estimation of the explosion hazard $[3,4]$. Depending on the classification, they distinguish zones in which the explosive atmosphere may be formed to a different degree and with different probability. The problem lies in the fact that the zones can be established individually, in view of the localization and the steps specified in respective guidelines. They slightly differ in content, but always give the user some freedom as to the size and classification of zones.

\footnotetext{
*Corresponding author: lukasz.zabrzeski@agh.edu.pl
} 


\section{Principles of determining the zones}

The explosion hazard is defined as potential occurrence of explosive atmosphere generated when flammable substances mix with the air, and also outbursts which may result in injuries, death or material damage [5]. As already mentioned, the explosive mixture is formed when about 5 to $15 \%$ of natural gas is present in the air. These are Lower Explosive Limit (LWL) and Upper Explosive Limit (UEL).

There are a few papers containing guidelines specifying how to design explosive hazard zones. Among the most important ones are Technical Standard of the Chamber of the Natural Gas Industry ST-IGG-0401 of 2015 [6], British standard of 2013 issued by the Institution of Gas Engineers \& Managers IGEM/SR/25 Edition 2 [7] and standard PN-EN 60079-10-1 of 2016 [8], based on standard IEC 60079-10-1:2015 RLV [9]. All they recommend the explosive zones to be designed individually for a specific case. They offer guidelines to follow, and which should not be ignored. There are also ready formulae, on the basis of which the shape and range of explosive zones can be obtained. Importantly, in each case the zones should be classified as zone 0 , zone 1 and zone 2. Basing on standard [8] and IGG standard [6], the zone can be identified depending on the probability of occurrence of explosive atmosphere or degree of emission and efficiency of ventilation. In the British standard, the zones depend on the probability of occurrence of explosive atmosphere, giving the ventilation system efficiency classes from poor to more than adequate. In both cases in zone 0 explosions take place continuously over a long time, or with high frequency. In zone 1 the probability of occurrence of explosive atmosphere is associated with regular operation of the installation. In zone 2 probability of occurrence of explosive atmosphere during regular operation of the installation is low; such effects are rare, if at all, and short. Among the degrees of emission, we can distinguish continuous, primary and secondary degrees, in the order of decreasing frequency of occurrence and duration of emission of flammable substances. Ventilation is defined on the basis of its availability and reliability. It should have appropriate quality especially when the second degree emissions tend to pass to higher groups.

Unlike its other counterparts, standard presented in [8] gives recommendations on how to calculate characteristic emission parameters, without giving ready formulae for the range of the zones. The only direct guideline is a plot on the basis of which the distance from the emission source can be safely determined in a graphic form, if the characteristic of the emission, i.e. density of medium, yield and lower explosive limit are known.

\section{Character of source of emission}

When determining explosive zones attention should be paid to the type of medium, conditions in which it mixes with the air, what is the pressure of emission and character of its source. Standards [6] and [7] mainly concentrate on natural gas, while standard [8] also provides guidelines for substances of higher density. The character of the source is defined by its surface, shape and spatial localization. In Poland the gas sector relies generally on IGG standard [6]. The character of emission and surface of source of emission are the main parameters here. It was assumed that gas propagates in natural-turbulent or jet mode. Unlike [7] and [8] there is no division to the vent pipe terminations. The direction of the release pipes is extremely important because of the high pressure involved. The zone extent will be larger towards the propagating emission than in the case of a vertical pipe. As to the rooms, the British standard [7] and standard [8] also define the effect on the quality of ventilation of neighbouring objects and also wind speed for natural ventilation (British standard [7] also includes a map of Great Britain with wind speed isolines). 


\section{Sealing elements}

An important assumption should be made that in the lack of possibility to measure the surface of the opening (especially when assuming unexpected emissions resulting from leaky sealing elements), it equals to $0.25 \mathrm{~mm}^{2}$ (with exception of [8], where it depends on type of sealed parts - fixed or moving). The division is also made for various pressures. Here the focus is on high pressure intervals. A spherical shape of the zone is assumed. The probability of occurrence of explosive atmosphere is very low therefore we have to do with zone 2 .

In standard IGEM/SR/25 each type of sealing elements has its own guidelines determining possible shapes of zones, with a sphere as the basic one. For comparison's sake, the radius of a sphere defining the zone for sealing elements at gas pressure of $5 \mathrm{MPa}$ equalled to $1.6 \mathrm{~m}$ in IGG standard [6]; according to IGEM [7] the radius totalled to $1.0 \mathrm{~m}$ (assuming undisturbed natural ventilation).

\section{Release pipes}

For the sake of showing the differences in the obtained results, emphasis was put on the emission from release pipes in high pressure pipelines, depending on the applied standards. The calculations were based on a British standard [7], IGG standard [6] and standard [8]. The release pipe ( $100 \mathrm{~mm}$ of diameter) is a source of emission; its orifice is placed 3 meters above the terrain surface. Natural gas is discharged from this pipe to the atmosphere at a pressure of $5 \mathrm{MPa}$. Natural gas has a molar mass of $16.5 \mathrm{~kg} / \mathrm{kmol}$ and temperature $5^{\circ} \mathrm{C}$. All the guidelines suggest a different shape for the zone: British standard [6] -2 cylinders of different size, and a sphere; IGG [6] - a sphere and a cone; standard [8] - the shape should be defined by the person who defines the explosion hazard.

Standard [8] provides shapes, depending on the gas pressure and certainty of direction of propagation, as in figure 1: for low and high pressure in the lack of certainty as to the emission direction - sphere; for high pressure at known emission direction - cylinder or a truncated cone decreasing the radius towards the source of emission. The calculated dimensions for given emission parameters are given in tables 1-3, and are schematically presented in Figure 3. The shape of the zone calculated after [8] has not been accounted for in the figure because authors of the standard did not provide respective formulae, so it can be equal to the calculated one or smaller, depending on the conditions. Thus defined hazardous distance can be treated as maximum for high pressure natural gas emissions from release pipes (jet flux). This value is smaller than the obtained radius of a sphere obtained with the presently applied IGG standard [6].

The range of the hazardous zone in the form of a sphere was calculated on the basis of [6] and equation (1), where $p_{r}$ - working pressure of gas in the source of emission [MPa], $F$ - cross section of orifice, being a source of gas emission $\left[\mathrm{mm}^{2}\right]$. The dependence of the radius of the sphere on the gas pressure and diameter of the release pipe is additionally presented in Figure 2. The hazardous zone at the base of the cone [6] was calculated with formula (2), where $d$ is a diameter of the release orifice [mm].

The size of the zone in [7] was calculated on the basis of tables (in [7]), dedicated to the respective parameters of emission source. The hazardous zone in [8] was based on a plot of the range vs. character of source of emission, which for non-choked release can be determined with equations (3) and (4), where $W_{g}$ is mass release rate of gas $[\mathrm{kg} / \mathrm{s}], \rho_{g}$ is gas density $\left[\mathrm{kg} / \mathrm{m}^{3}\right], k$ is the safety attributed to $L F L$ (typically between 0.5 and 1.0 ), $L F L$ is lower flammable limit (for natural gas approximately $5 \%$ ), $C_{d}$ is discharge coefficient (dimensionless) which is characteristic of the release openings and which accounts for the effects of turbulence and viscosity (for rounded orifices 0.95 to 0.99 ), $S$ is the cross section of the opening hole), through which the fluid is released $\left[\mathrm{m}^{2}\right], p$ is pressure inside pipe $[\mathrm{Pa}]$, 
$M$ is molar mass of gas or vapour [kg/kmol], $Z$ is compressibility factor (dimensionless), $R$ is universal gas constant $\left(8314.3 \mathrm{~J} \cdot \mathrm{kmol}^{-1} \cdot \mathrm{K}^{-1}\right), T$ is absolute temperature of the gas $[\mathrm{K}], \gamma$ is polytropic index of adiabatic expansion or ratio of specific heats and $p_{a}$ is atmospheric pressure $(101324.7 \mathrm{~Pa})$. Values of coefficients $k$ and $C_{d}$ were assumed as equal to 1 . Coefficient $Z$ was calculated analogously as in [10], making use of Peng-Robinson equation and Newton-Raphson method, whereas adiabatic exponent $\gamma$ with the method as in [11].

$$
\begin{gathered}
Z_{R}=0,33 \cdot F^{0,5} \cdot\left(p_{r}+0,1\right)^{0,5} \\
Z_{S}=0,175 \cdot d \\
\text { Release characteristic }=\frac{W_{g}}{\rho_{g} \cdot k \cdot L F L} \\
W_{g}=C_{d} \cdot S \cdot p \cdot \sqrt{\frac{M}{Z \cdot R \cdot T} \frac{2 \cdot \gamma}{\gamma-1}\left[1-\left(\frac{p_{a}}{p}\right)^{\frac{1-\gamma}{\gamma}}\right]}\left(\frac{p_{a}}{p}\right)^{\frac{1}{\gamma}}
\end{gathered}
$$

Table 1. Extent of hazardous range, after [6]

\begin{tabular}{|l|c|c|c|}
\hline \multicolumn{3}{|c|}{ Standard ST-IGG-0401:2015 } \\
\hline Parameter & Symbol & Value & Unit \\
\hline Radius of sphere - zone 2 & $Z_{r}$ & 66,05 & $\mathrm{~m}$ \\
\hline Radius of base of cone - zone 2 & $Z_{s}$ & 17,50 & $\mathrm{~m}$ \\
\hline Radius of sphere - zone 1 & $Z$ & 1,00 & $\mathrm{~m}$ \\
\hline
\end{tabular}

Table 2. Extent of hazardous range, after [7]

\begin{tabular}{|l|c|c|c|}
\hline \multicolumn{4}{|c|}{ Standard IGEM/SR/25 Edition 2 } \\
\hline \multicolumn{1}{|c|}{ Parameter } & Symbol & Value & Unit \\
\hline $\begin{array}{l}\text { Height of zone 2 below orifice, being result } \\
\text { of lower dispersion }\end{array}$ & $X_{L}$ & 0,20 & $\mathrm{~m}$ \\
\hline Height of zone above release pipe & $X_{h}$ & 120,00 & $\mathrm{~m}$ \\
\hline $\begin{array}{l}\text { Radius of zone 2 from release orifice, } \\
\text { being result of lower dispersion }\end{array}$ & $X_{k}$ & 12,00 & $\mathrm{~m}$ \\
\hline Radius of zone 1 from release orifice & $X_{s}$ & 1,00 & $\mathrm{~m}$ \\
\hline Radius of zone 2 from release orifice & $X_{r}$ & 30,00 & $\mathrm{~m}$ \\
\hline
\end{tabular}


Table 3. Maximum extent of hazardous zone, after [8]

\begin{tabular}{|c|c|c|c|}
\hline \multicolumn{3}{|c|}{ Standard PN-EN 60079-10-1 } \\
\hline \multicolumn{1}{|c|}{ Parameter } & Symbol & Value & Unit \\
\hline $\begin{array}{l}\text { Range of zone (height of cylinder or radius } \\
\text { of sphere) }\end{array}$ & $r$ & 45,61 & $\mathrm{~m}$ \\
\hline
\end{tabular}
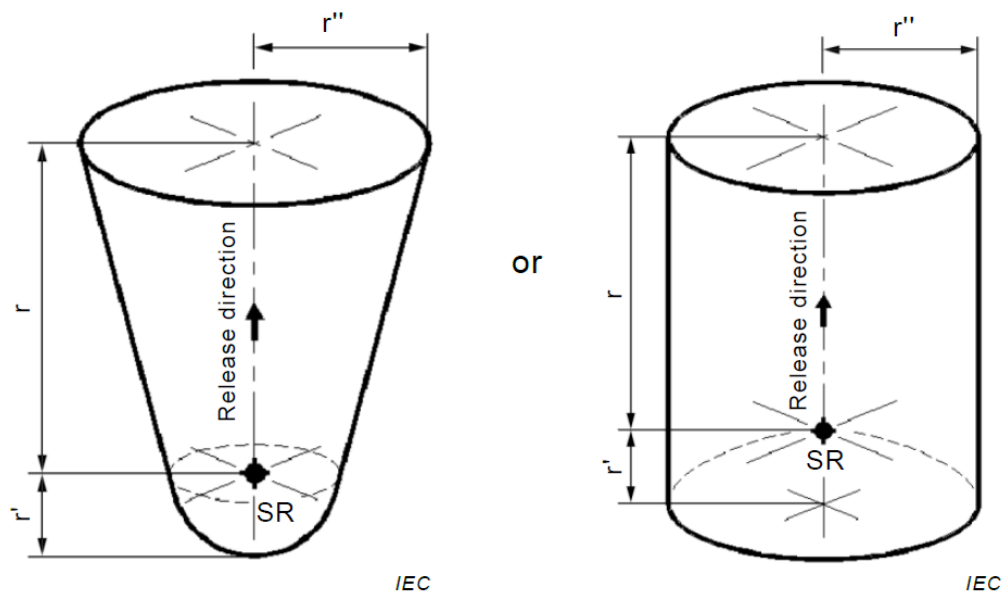

Fig. 1. Proposed hazardous zones shapes in case of high pressure of gas, where $r$ is main extent of the hazardous area to be defined considering the estimated hazardous distance, $r$ ' and $r$ ' are secondary extents of hazardous area to be defined considering release behaviour, $S R$ is release source. [8]

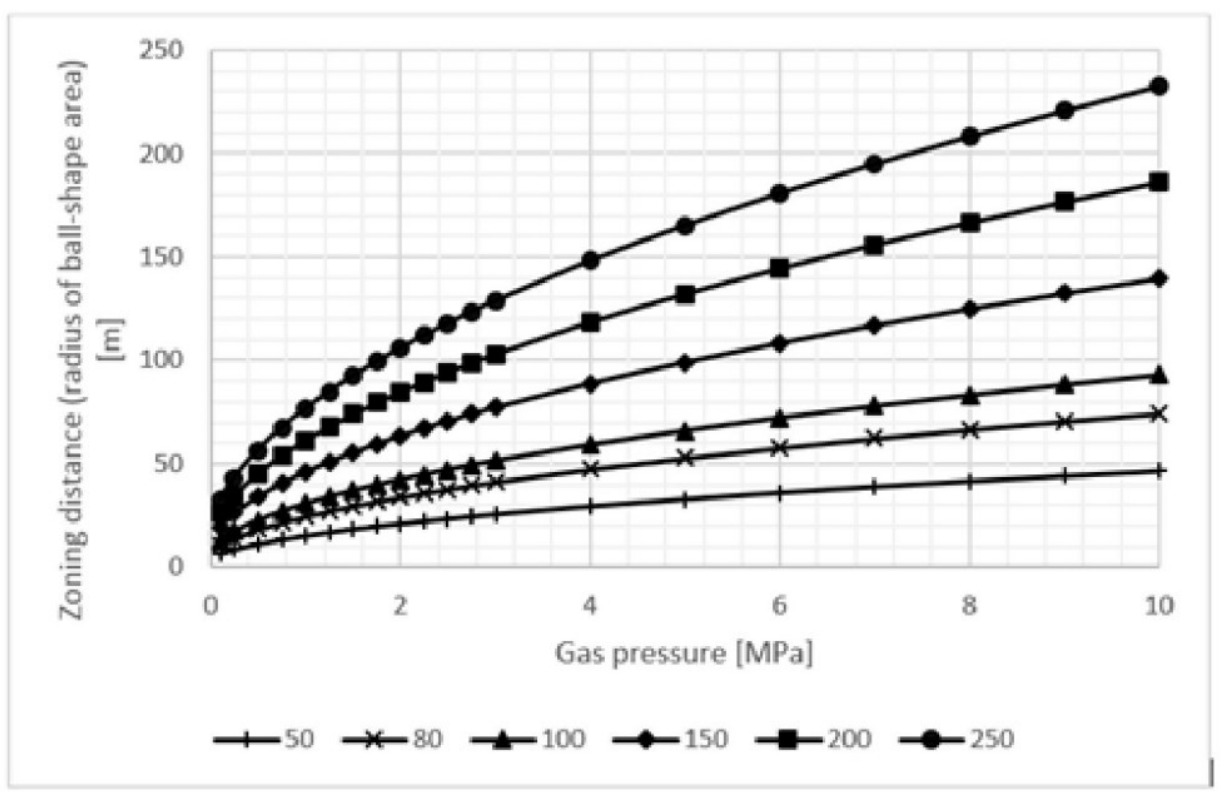

Fig. 2. Extent of hazardous zone 2 - radius of sphere, for various diameters of release pipes [mm], depending on gas pressure, after [6] 


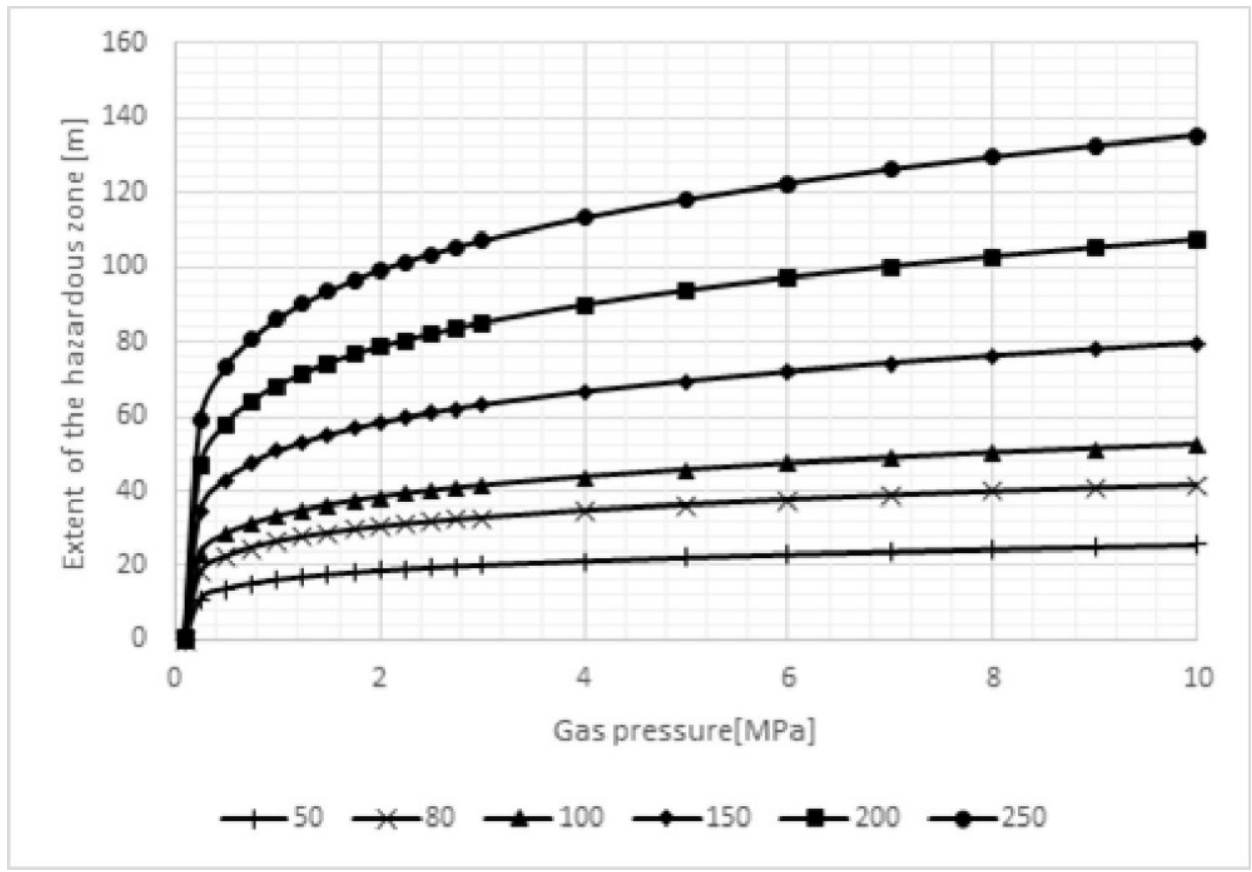

Fig. 3. Extent of hazardous zone or area where flammable gas may occur for different nominal pipe diameters, depending on gas pressure in pipe, after [8]

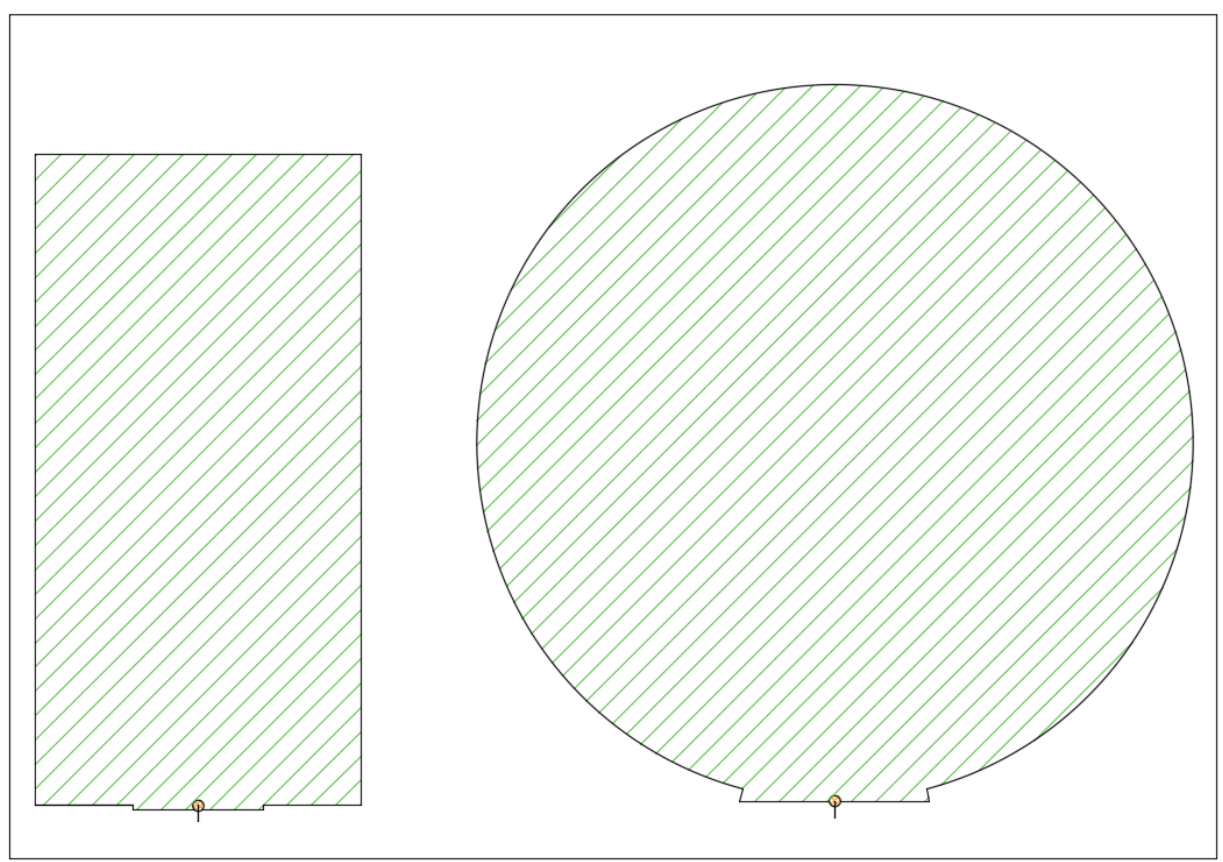

Fig. 4. Hazardous zones for analysed example of release pipe after standard IGEM [7] (left) and IGG [6] (right) 


\section{Discussion and conclusions}

The analysis of the results of calculations performed for the assumed case in line with respective guidelines reveals that each approach brings about different results. Values calculated after IGG standard [6] are definitely highest. Lower results were obtained for standard [8], which became applicable in Poland in 2016, whereas the lowest for the British standard [7]. It should be emphasized that standards are not obligatory according to the Polish law, though the evaluation of the gas explosive hazard is obligatory. Hence, ready-made guidelines are provided for the hazard zones designers. They are part of the assessment or own methodics, which should be approved by the respective authorities.

The hazardous zones can be evaluated in a number of ways and they can significantly differ in their shape and extent, as seen in figures 2-4. Attention should be paid to the difference in the dependence between the extent and the pressure. The influence of the diameter of the release pipes on the zone area in IGG standard [6] and standard [8] is similar, the increase of the extent of the zone in [8] for pressures lower than ca. $1 \mathrm{MPa}$ is considerably higher than in [6]. For higher pressures the situation is reverse - the increase of hazardous zones in [8] is small ( $8 \%$ for DN100 and pressures $4 \mathrm{MPa}$ and $6 \mathrm{MPa})$, whereas in [6] it is maintained on a relatively high level (increase of $22 \%$ for DN100 and pressures $4 \mathrm{MPa}$ and $6 \mathrm{MPa})$.

Hazardous zones in natural gas installations should be determined individually in each case. Importantly, none of the factors which may affect the shape of the zones should be ignored. The analysis of the calculations reveals that the difference in calculations for horizontal extents may significantly differ (in the analysed example - over twice; according to IGG the horizontal extent totals to $66 \mathrm{~m}$, according to IGEM it is $30 \mathrm{~m}$ ). The differences result from assumptions taken in line with the respective guidelines. Unfortunately there are no documented research works, which would prove the congruence of any of them with reality. It is worth observing that the extents calculated according to the Polish guidelines are very high, and the atmospheres are not likely to form on such large areas. Therefore it is crucial to find such shapes of hazardous zones as to maintain appropriate safety level at real probability of hazardous zones formation, and the zones will not be redimensioned.

This work has been prepared within the statutory research of Department of Natural Gas Engineering, Drilling, Oil and Gas Faculty, number: 11.11.190.555

\section{References}

1. D. A. Crowl, Understanding Explosions (Wiley, 2003)

2. W. E. Baker, P. A. Cox, J. J. Kulesz, R. A. Strehlow, P. S. Westine, Explosion Hazards and Evaluation (Elsevier, 1983)

3. M. Łaciak, Bezpieczeństwo eksploatacji urządzeń, instalacji i sieci gazowych (Tarbonus, KrakówTarnobrzeg, 2013)

4. T. Sawicki, Bezpieczeństwo Pracy: nauka i praktyka, 11, 1 (2005)

5. M. Woliński, G. Ogrodnik, J. Tomczuk, Ocena zagrożenia wybuchem. (Szkoła Główna Służby Pożarniczej, Warszawa 2007)

6. *** ST-IGG-0401:2015 Sieci Gazowe Strefy Zagrożenia Wybuchem Ocena i Wyznaczanie. (Izba Gospodarcza Gazownictwa, Warszawa 2015)

7. *** IGEM/SR/25 Edition 2 with Amendments August 2013 Communication 1748. Hazardous area classification of Natural Gas installations. (The Institution of Gas Engineers and Managers, 2010)

8. *** PN-EN 60079-10-1 Atmosfery wybuchowe Częśc 10-1: Klasyfikacja przestrzeni Gazowe atmosfery wybuchowe. (Polski Komitet Normalizacyjny, Warszawa 2016)

9. *** IEC 60079-10-1:2015 RLV Explosive atmospheres - Part 10-1: Classification of areas - Explosive gas atmospheres (International Electrotechnical Commission, 2015) 
10. T. Blacharski, P. Janusz, M. Kaliski, Ł. Zabrzeski, AGH Drilling, Oil, Gas 332 (2016)

11. Ł. Zabrzeski, P. Janusz, K. Liszka, M. Łaciak, A. Szurlej, AGH Drilling, Oil, Gas (to be published) 